\title{
Parental choice and selective non-treatment of deformed newborns: a view from mid-Atlantic
}

\author{
J K Mason Faculty of Law, University of Edinburgh and David W Meyers Napa, California
}

\section{Authors' abstract}

This paper traces the development of parental rights to accept or to refuse treatment for a defective newborn infant in the United Kingdom and in the United States of America; its main purpose is to explore the common trends from which an acceptable policy may be derived. It is probable that the British law on parental decision-making in respect of infants suffering from Down's syndrome is to be found in the civil case of In $\mathrm{Re} B$ rather than in the criminal case of $\mathrm{R} v$ Arthur. United States court decisions are strongly influenced by constitutional law and reflect the right to personal privacy. The position on each side of the Atlantic seems very similar but this similarity includes a sense of uncertainty as to legal responsibility. There is a case for agreed guidelines and a suggested format is offered for consideration.

\section{Introduction}

The trend of recent decisions in the United States has been to allow the family of the terminally-ill, incompetent adult patient to elect against further lifesustaining treatment when the attending physicians assess the prognosis as hopeless. At the same time, recent cases in the United Kingdom have recognised the right of parents to consent and to control proposed medical treatment for their children but they also demonstrate the limitations upon and the duties concomitant with such rights.

It is only in the last decade or so that questions concerned with the selective non-treatment of birthdefective newborns have been aired openly. Few clear guidelines have been proposed by either the legal or medical professions. Do parents have a right to refuse treatment for their hopelessly ill newborn infant? And if so, does it extend to other cases involving serious and permanent, but not immediately life-threatening, defect? The uncertainty which prevails aids no one and, consequently, we thought it might be useful to review the relevant parental choice-of-treatment decisions which have been taken in the courts of the

\section{Key words}

Defective newborns; Down's syndrome; neural tube defects; selective non-treatment; parental rights; UK and US court decisions.
United Kingdom and of the United States. From this it $\vec{N}$ might be possible to deduce a common thread and, i thence, to derive an acceptable policy.

\section{Current British position}

The attitude of the British courts to selective nontreatment of the neonate - or, indeed, to any aspect of patient care - is epitomised in the direction of Farquharson J to the jury in $R v$ Arthur (1): 'I imagine', he said, 'that you will think long and hard before concluding that eminent doctors have evolved standards that amount to committing a crime' (2). In effect, the judge was giving express approval in the criminal courts to what has become known as the Bolam (3) principle in civil litigation. The essence of this is that a doctor is not negligent - neither in criminal nor in civil law - if he acts in accordance with a practice which is accepted as proper by a responsible body of medical opinion at the time.

This professional standard is, however, not absolute as the British courts have always had the power to hold such a standard to be insufficient (4). This power has recently been emphasised. Thus we have Sir John Donaldson MR qualifying Bolam to the extent of affirming specifically that 'the definition of the duty of care is a matter for the law and for the court . . . In a word, the law will not permit the medical profession to play God' (5). Lord Scarman also found an extension of the Bolam principle to have disturbing implications in that 'it [left] the determination of a legal duty to the judgement of doctors' (6). Nevertheless, the principle of the professional standard is deeply entrenched in British law. That being so, we must look to responsible medical opinion to illustrate the current position.

Lorber (7) has laid down clinical guidelines for the selective treatment of infants with neural tube defects. His six criteria which indicate an unfavourable prognosis and, therefore, determine that an infant will have no surgical treatment, are said to have become a basis for selection in the United Kingdom and many other countries. Selective non-treatment of this type has the clear backing of the British Medical Association (8) and, by implication, of the law - the Director of Public Prosecutions refused to prosecute after a police investigation into the non-treatment of a spina bifida baby (9). However, more generalised non-treatment 
guidelines have neither been widely aired nor accepted, neither by the law nor by medicine.

Certain principles are considered fundamental in non-treatment cases. Untreated infants are given nursing care and are fed on demand but they are not tube-fed, nor are they given antibiotics when infected; indeed, allowing such children to go home is discouraged lest they be given intensive treatment, which includes antibiotics. Above all lies a central dependence on parental decision aided by counselling. Parental consent is also at the heart of the British Medical Association's thinking - 'There is no justification for usurping parents' rights' (10); there is also substantial academic legal support for the principle - Glanville Williams has said: 'The criminal law should stay its hand...the decision of the parents should prevail ' (11). In practice, parental consent is determined to a large extent by the doctor's counsel which, in turn, depends upon his motivation (12). The two are closely interlinked as was demonstrated in the only apposite case to come before the British courts In $\operatorname{Re} B$ (A Minor) (13).

In this case, an infant was born suffering from Down's syndrome with the added complication of duodenal atresia; the parents refused permission for an operation without which death was inevitable. The child was made a Ward of Court and, after some uncertainty, the case came before the Court of Appeal which authorised the local authority themselves to authorise and direct that the operation be carried out. In so doing, it was held that there was no evidence that the infant's short life was likely to be an intolerable one and it was further asked: 'Was the child's life going to be so demonstrably awful that she should be condemned to die? . . . It was wrong that the child's life should be terminated because, in addition to being a mongol, she had another disability' (per Templeman LJ.

From this, there seems no doubt, that, firstly, the court was, as it is bound to do, putting the interests of the child first - 'the judge of first instance had erred because he was influenced by the views of the parents instead of deciding what was in the best interests of the child' - and was unconvinced by the doctrine of parental autonomy. Secondly, it was, by implication, accepting the Lorber concept of selective nontreatment in the case of children whose prognosis was 'intolerable'. As to the first, the British Medical Association were of the contrary opinion saying that, in the case of a Down's syndrome baby with congenital defects: 'treatment may reasonably be withheld if that is the consensus reached by the parents and at least two doctors ... For most babies unwanted by their families, the present reality is a miserable life-time in an NHS [National Health Service] institution' (14).

Professor Lorber is reported (10) as urging that criteria similar to those used in children with neural tube defects should be developed for the treatment of Down's syndrome children - including that the decision should be parental. However, an attempt to equate the two conditions is illogical. Selective nontreatment of spina bifida cases is based on the expectation of pain and suffering, which does not apply in the Down's syndrome case. From the viewpoint of the Down's baby, the only test of treatment can be that of surgical feasibility and such a test is inapplicable to the uncomplicated case - just as it is to the infant who is mentally retarded from any other cause and who is demonstrating every will to live.

Which leads to the only other relevant reported British case $-R v$ Arthur (1). This case can be discussed from many aspects but we are here concerned with the rights of the parents in respect of a neonate. From this point of view, the important facts are that the infant's notes were annotated 'Parents do not wish it to survive. Nursing care only'; that, at the time the notes were written, there was no evidence of any physical defect in the baby; that feeding was withheld and large doses of dihydrocodeine were prescribed in order to minimise hunger pains; and that the baby died 69 hours after birth. The fact that $\mathrm{Dr}$ Arthur was acquitted of attempted murder is immaterial because there is no evidence that the parents' involvement was questioned in the light of $\operatorname{Re} B$ which had been heard some months before his trial. The parents' rights in the case must, therefore, be considered from other angles.

There is considerable British statute law which protects children against neglect and which is relevant to the Arthur situation. Probably the most significant is the Children Act 1975, s 85 which prohibits a parent from surrendering parental duties. The Children and Young Persons Act 1933, s 1 creates an offence of wilful neglect and, while the definition of wilful is in some ways contentious, a deliberate decision not to feed an infant must fall into that category. Neglect to the detriment of the child's health is also a main reason for bringing a child into the care of the local authority (Children and Young Persons Act 1969, s 1).

As to case law, it seems difficult to accept that giving the infant over to a doctor who intends to deprive it of food would be a sufficient defence against charges of neglect (15); rather, the concept of a mother refusing to feed her baby is of the same order as concealment of birth. A mother can commit infanticide by omission and, given the necessary mens rea, neglect of a child could be charged as manslaughter (16). It is relevant that it was said in $\operatorname{Re} B$ by Dunn LJ: 'She should be put in the same position as any other mongol child and must be given the chance to live an existence' (13); it is clear that the idea of failing to feed a physically normal Down's syndrome infant never occurred to the Lord Justice. The precedent in $\operatorname{Re} B$ is supported, somewhat obliquely, by Gillick $v$ West Norfolk and Wisbeach $A H A$ [Area Health Authority] (17). In that case, the question of control of the medical treatment of a minor was decided in the Court of Appeal in favour of the parents but the decision was based on parental duties; duties and rights were regarded as indivisible and the duty must be to the advantage of the child, otherwise the courts may intervene. The decision in the same case in 
the House of Lords, being essentially concerned with the mental capacity of teenage girls, does not alter this principle.

The case of McKay $v$ Essex $A H A$ (18) is also persuasive. This was, effectively, a wrongful life suit in which it was held: 'To impose [a duty to take away life by means of abortion] towards the child would be to make a further inroad ... . into the sanctity of human life which would be contrary to public policy' (per Stephenson LJ). If this is true of the fetus, it must surely be true of the neonate and there can be no duty to the child to take away his life because, for example, he is likely to be institutionalised. And it would be taking a very big step to extrapolate that a mother's right to abortion extends to a right to neonaticide.

Sherlock (19) has pointed out that the concept of parental decisions in circumstances where the child has no interest in death strikes at the heart of all child neglect legislation. The British Medical Association has recently concluded: 'A malformed infant has the same rights as a normal infant. It follows that ordinary non-medical care which is necessary for the maintenance of the life of a normal infant should not be withheld from a malformed infant . . . This includes making sure that the child was fed unless there were clinical reasons to the contrary'. There are strong reasons for supposing that the British law as regards parental decisions concerning the survival of infants suffering from Down's syndrome is to be found in $R e$ $B$ and not in Arthur.

It would seem that the British law on parental consent to selective non-treatment is clear in principle but not in detail and the general understanding of the situation is clouded by a failure to distinguish between physical and mental defect. There must be a good case for closer guidelines; working and making decisions in a partial vacuum cannot be satisfactory.

\section{Current American position}

The American position on parents' rights to elect nontreatment for their newborns is significantly affected by constitutional law. Parental prerogatives to raise, educate, religiously instruct and nurture children have been held to be protected under the United States constitution (20); they are fundamental components of the rights to personal privacy (21). These prerogatives are not absolute. The State, as substitute parent, has a significant interest in protecting minors under its parens patriae powers. It may override parental choice where it is necessary not to 'jeopardise the health or safety of the child' (22). The court will make the child a ward and authorise treatment when the parents refuse consent to medical care which is obviously necessary to save the child's life (23). The position is far less certain when the medical evidence is unclear as to the benefit of treatment.

Treatment will often be ordered where the benefit, although not lifesaving, is clear and the risk is minimal, unless the degree of benefit is small. The parental choice of non-treatment will normally be honoured when benefit is unclear or is possible only at great risk or suffering.

The case $R e$ Phillip $B$ (24), while not involving a newborn, shows the degree of deference that may be afforded parental choice. A twelve-year-old boy suffering from Down's syndrome had a heart defect amenable to correction with only a five - ten per cent risk of surgical mortality. Without surgery, death would occur, slowly and painfully, within twenty years. The courts upheld the parents' refusal of consent, this not being found to constitute a refusal to provide adequate medical care. Several years later custody of the boy was ordered to be transferred to third party guardians to further his best interests. However, by then, it may have been too late for the corrective surgery (25).

Few cases involving parental choices of nontreatment for their deformed newborns have reached the American courts (26). This is explained, in part, by the deference given to parental rights referred to above and also by that given by prosecutors and courts to the rights of physicians to treat in accordance with the precepts of their professional ethics. There is also the traditional reluctance of the courts to intervene in the private decision-making between doctors, family and patient. The private resolution of the vast majority of these cases has not prompted any reports of significant or widespread abuse.

The few cases which have reached the courts and which have been reported have not produced consistent results. In several cases (27) the trial judges followed a 'medical feasibility' test, holding that surgery must be undertaken if it was feasible - ie could be technically accomplished - and was life-sustaining; no appeals followed. Any qualitative component in the decision-making process in such cases was expressly eschewed. One court, in ordering surgery to correct a tracheo-oesophageal fistula in a brain-damaged newborn, stated:

'. . . the issue before the Court is not the prospective quality of the life to be preserved, but the medical possibility of the proposed treatment compared with the almost certain risk of death should treatment be withheld' (28).

Another court had no difficulty in compelling lifesaving surgery where a spina bifida birth defect was significant but did not affect the brain and was not expected to prevent relatively normal intellectual development (29). On the other hand, the decision of parents and physicians not to treat or feed artificially has been upheld where the infant's defects were irreversibly terminal (30).

The most difficult cases are those in which the child has been born with significant abnormalities, physical and mental, but would probably survive with aggressive treatment (31). In these cases, the courts have refused to intervene, given the decision of parents and physicians not to treat and given evidence showing 
the decision to be supported by reasonable medical opinion. When faced with multiple, severe defects at birth, the parents were, in effect, allowed to choose one reasonable medical option, that of non-treatment, over another, that of treatment. The mixed results of these, fortunately very few, cases highlight the need for realistic, flexible guidelines for selective nontreatment.

\section{Suggested guidelines for the exercise of parental choice}

Legal decisions are an inadequate basis for establishing attitudes in this very difficult area; the precedents are too few and are not always consistent. We suggest there should be guidelines towards establishing norms of parental and medical conduct which would be approved in litigation, whether this be civil or criminal in nature.

The parents, who have conceived the infant and who have the responsibility to raise it, should be given the right, within closely and carefully drawn confines, to elect non-treatment when their child is born severely deformed. Additionally, society should not, without strong reason, dictate standards to physicians which compel treatment in circumstances in which many ethically-minded doctors would feel it was medically inappropriate.

At the same time, any guidelines must give primacy to fostering and preserving the lives of the newborn. None the less, this is not an absolute concept. Quality of life - not in the sense of social utility or worth but solely as judged by a physiological existence without intolerable pain or suffering - may properly enter such treatment decisions (32). Such guidelines must also allow for advances in medical science and should foster, not hinder, the formation of medical practice consensus in such cases. With few exceptions, good medical practice makes good law and the law follows good medical practice. The keynote here must be productive or beneficial treatment. Treatment must be presumptively indicated if it will improve the living conditions of the infant to a level of tolerable pain and suffering and will allow the infant some ability to interact with his or her fellows and environment.

With these premises in mind, the following guidelines may serve to increase discussion, formation of opinion and social acceptability of a parental choice not always to treat their deformed newborns. Guidelines which are approved by the medical profession may well avoid intrusion of legislation into this intensely personal area of decision-making. Legislation, other than that which is purely enabling, is not likely to provide the necessary flexibility and it removes decision-making from those who must deal with the consequences of their actions.

If positive treatment is necessary for the infant's survival, we suggest the law should respect parental decisions not to treat their newborn when:

1. the decision is concurred in as being medically proper by the attending physician and by at least one other independent, qualified physician, preferably a neonatologist of paediatrician;

2. the medical reasons for the decision not to treat (the prognosis) are entered in the medical record by the physician and are concurred in by the consultant;

3. the parents have been fully informed of the infant's diagnosis and prognosis with and without any reasonably available treatment; of the risks, nature and benefits of each such treatment; and of any other material facts bearing on the infant's condition and the treatment/non-treatment decision, so that they may give, or refuse, an information-based consent. The explanation and their decision should be likewise entered in the case notes and be witnessed;

4. the judgements required of parents and physicians have been made in good faith with the best interests of the infant as the guiding principle;

5. such affirmative treatment has, when necessary, continued after birth until a clear prognosis can be given with reasonable medical certainty that the infant falls within one of the categories set out below:

a. that death is highly probable and is expected within a reasonably short time, say one year, regardless of treatment; or

b. that there is no reasonable possibility that the infant will be able to participate to any degree in human relationships or experiences with others requiring some interaction or response; or

c. that treatment cannot obviate or alleviate an intolerable level of chronic pain (33) which would make continued life-sustaining treatment inhumane.

We believe that manual feeding, not involving medical intervention, should be continued in any circumstances when the infant is capable of taking nourishment by mouth.

In the United States, it may be wise to involve an institutional prognosis or ethics committee in at least the more difficult of such cases. Such duties are not currently envisaged for ethical committees in the United Kingdom where the need for an intermediate between the bedside and the courts is, perhaps, less apparent. Should there be any dispute, doubt or disagreement between any of the participants in the decision-making process as to prognosis, standard of care or motive, prompt petition for court review is proper while treatment continues.

The burden to the family is not a matter that physicians should be compelled to evaluate or to act upon. The allocation of scarce treatment resources in such cases is a real limiting factor but is one which is imposed by factors beyond the control of physician or parents - as well as being beyond the scope of this article.

\section{Conclusion}

The position on both sides of the Atlantic-British and American - in this complex area seems remarkably similar in that: 
1. both recognise the importance of respecting parental decisions but emphasise that the court will intervene in selected cases and may overrule the parents if that is necessary to protect the best interests of the child which are the paramount concern;

2. few cases of selective non-treatment have reached the courts, which indicates that most difficult decisions are made, when necessary, within the private context of the patient/physician/parent relationship;

3. there is no evident abuse in this private decisionmaking process;

4. although initial efforts have been made, no consensus exists on articulated standards for selective non-treatment of the defective neonate;

5. the few cases reaching the courts have not produced very helpful or consistent guidance for parents or physicians; in some part, this may be due to the lack of accepted standards of good medical practice.

Physicians and parents find themselves operating in this area in what is, largely, an uncertain legal ambience. The risk of prosecution, small though it may be, does not provide the best backdrop for informed and compassionate care of the defective neonate.

Legislation represents the other extreme to the present situation. Should legislation be regarded by the public as essential, it should be flexible enough to permit humane decision-making in individual cases and, while being inevitably restrictive, it must be simultaneously enabling. The medical profession has considerable antipathy to control by statute. However, legislation may be perceived as being the only available alternative unless accepted guidelines are drawn up and adopted by the profession, preferably in dialogue with the law and with organisations speaking for the rights of the handicapped. The aim of such guidelines should be to set out standards which are legally acceptable and which the medical profession can apply. It is hoped that this article may assist in that process.

f $K$ Mason MD, FRCPath, DMf is Regius Professor (Emeritus) of Forensic Medicine, Faculty of Law, Edinburgh University. David W Meyers $B A, \mathcal{F} D, L L M$ is a member of the California Bar, Napa, California.

\section{References}

(1) The Times 1981 Nov 6: 1,12.

(2) Quoted by Brahams D, Brahams M. R v Arthur - is legislation appropriate? (1981) 78 Law Society gazette 1342.

(3) Bolam v Friern Hospital Management Committee [1979] 1 WLR 582.
(4) Norrie K McK. Standards of disclosure. 1984 Scots law times 237.

(5) In Sidaway $v$ Board of Governors of the Bethlem Royal Hospital and Others [1984] 2 WLR 778, CA.

(6) In Sidaway [1985] 2 WLR 480, HL.

(7) Lorber J, Salfield SAW. Result of selective treatment of spina bifida cystica. Archives of diseases of childhood 1981; 56: 822-830.

(8) Anonymous. Death without concealment [editorial] British medical journal 1981; 283: 1629-1630.

(9) The Times 1981 Oct 6: 1.

(10) Anonymous. The right to live and the right to die [editorial]. British medical journal 1981; 283: 569-570.

(11) The Times 1981 Aug 13; correspondence: 11.

(12) Campbell AGM. The right to be allowed to die. fournal of medical ethics 1983; 9: 136-140.

(13) [1981] 1 WLR 1421

(14) Anonymous. Paediatricians and the law [editorial]. British medical journal 1981; 283: 1280-1281.

(15) Watson v Nikolaisen [1955] 2 QB 286.

(16) $R v$ Sheppard [1981] AC 394.

(17) [1985] 2 WLR 413, CA; [1985] 3 WLR 830, HL.

(18) [1982] 2 WLR 890.

(19) Sherlock R. Selective non-treatment of newborns Fournal of medical ethics 1979; 5: 139-140.

(20) Pierce $v$ Soc of Sisters (1925) 268 US 510, 535; Meyer $v$ Nebraska (1923) 262 US 390, 399; Parham v $\mathcal{F R}$ (1979) 442 US 584, 602.

(21) Quilloin v Woolcott (1978) 434 US 246, 255.

(22) Wisconsin v Yoder (1972) 406 US 205.

(23) Jehovah's Witnesses of Wash $v$ King Co Hosp (1967, WD Wash) 278 FS, aff'd 390 US 598.

(24) (1979) 92 Cal App 3d 796, cert den 445 US 949.

(25) Guardianship of Phillip B (1981) 139 Cal App 3d 407.

(26) Weber $v$ Stony Brook Hospital (1983) NY, 456 NE 2d 1186, cert den (US) $104 \mathrm{~S}$ Ct 560; US $v$ University Hospital, State University of New York (1984 CA 2d, NY) 729 F 2d 144; Infant Doe v Bloomington Hospital (1982) Ind, Monroe Co Cir Ct No GU 8204-00, cert den (US) 104 S Ct 394; Re Cicero (1979) NY App, 421 NYS 2d 965; Matter of Baby F (1983) Ore, Coos Co Cir Ct No J 928; Maine Medical Center v Houle (1974) Maine, Cumberland Co Sup Ct No 74-145; In re McNulty (1978) Mass, Probate Ct No 1960. The cases are discussed in Meyers D M. Medico-legal implications of death and dying. Rochester, NY: Lawyers Co-operative Publishing Company, 1981: Ch 14.

(27) See reference 26: Houle and McNulty.

(28) See reference 26: Houle 452, quoted in Meyers.

(29) See reference 26: $\mathrm{Re}$ Cicero.

(30) See reference 26: Matter of Baby F. See also In Re Barry (1984) Fla App, 445 So 2d 365.

(31) See reference 26: Infant Doe; Weber v Stony Brook; US v University Hospital $N Y$.

(32) See reference (26): US v University Hospital NY (1984) 729 F 2d 144, 146; McCormick R A. To save or let die: the dilemma of modern medicine. Fournal of the American medical association 1974; 229: 172-176.

(33) Matter of Conroy (1985) NJ, 486 A 2d 1209. 